\title{
CLOSE NA WEB: INCORPORANDO FEMININOS DESEJÁVEIS
}

\author{
Weslei Lopes Silva ${ }^{l}$ \\ Juliana Gonzaga Jayme ${ }^{2}$
}

\begin{abstract}
RESUMO
Este artigo visa problematizar como um grupo de mulheres que se dedica ao comércio de strip-tease on-line se constitui enquanto strippers a partir de seu corpo para a atuação nesse mercado. Para tanto, as encenações que elas constroem em fotos e vídeos, bem como ante a webcam a partir do uso criativo e tecnológico do corpo, engendram femininos performáticos que exigem provisoriamente a destituição de si mesmas e a constituição de uma outra mulher (ou mesmo, outras mulheres) para os shows. Partindo das noções de incorporação e de performance de gênero, buscamos a reflexão sobre como elas ressignificam o corpo, incorporam discursos, gestos e atos, como estilizam o corpo em acordo com a mulher a ser performatizada para atrair e agradar aos clientes e, assim, alcançar maiores ganhos financeiros.
\end{abstract}

Palavras-chave: Corpo. Gênero. Web Strippers. Etnografia.

\section{A CLOSE UP IN THE WEB: EMBODYING DESIRABLE FEMININITIES}

\section{ABSTRACT}

This article intends to discuss how a group of women engaged in the striptease online commerce is constituted, through their bodies, as strippers. In that sense, the scenes that they build in photos and videos, as well as in front of the webcam with a creative and technological use of the body, engenders female performances that require

\footnotetext{
1 Professor do Departamento de Educação da Universidade de Itaúna, Brasil. wesleilop@gmail.com

${ }^{2}$ Professora do Departamento de Ciências Sociais da Pontifícia Universidade Católica de Minas Gerais, Brasil. julianajayme@pucminas.br
} 
provisionally the removal of themselves and the constitution of another woman (or even other women) in the shows. Based on the notions of gender, embodiment and performance, we seek to reflect on how they re-signify the body, incorporate speeches, gestures and acts as stylize the body in accordance with the woman to be performed in order to attract and please the customers and thus achieve greater financial gain.

Keywords: Body. Gender. Web strippers. Ethnography.

\section{INTRODUÇÃO}

Por que nossos

corpos deveriam

terminar na pele?

Donna Haraway

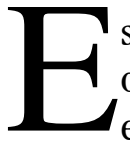
ste artigo parte de uma etnografia realizada com web strippers, cujo objetivo central foi analisar como algumas mulheres articulam a experiência de trabalhar no mercado de strip-tease on-line e, particularmente, como percebem e vivenciam o corpo nas interações com os clientes via internet (SILVA, 2014).

Para fazer a pesquisa de campo com as web strippers, o primeiro contato foi realizado em sites brasileiros que oferecem cenas ao vivo via webcam, por meio da compra de pacotes de minutos. Nesses espaços, geralmente, são oferecidas duas modalidades de salas: aquelas em que a exibição acontece para várias pessoas a mesmo tempo, e são mais baratas; e as salas privadas, onde a interação acontece entre a(o)s stripper(s) e aquele(a) que contratou o serviço. Nenhuma das strippers contatadas nesses sites, porém, aceitou o convite para participar da pesquisa. Após três meses de observação dos shows em salas coletivas em alguns sites ${ }^{4}$ desse tipo, e tendo anunciado a identidade de pesquisador a algumas strippers, explicando os objetivos da investigação, algumas delas manifestaram desinteresse ou falta de tempo para participar, outras

\footnotetext{
${ }^{3}$ Pesquisa de doutorado, sob orientação de Juliana Gonzaga Jayme. Escrito a quatro mãos, este texto tem como objetivo a análise da experiência de campo de apenas um dos autores.

${ }^{4}$ A pesquisa, nesta fase, ocorreu em grande parte no site LoveCam, (www.lovecam.com.br). Atualmente 0 site se hospeda no domínio UOL, e está disponível em $<$ www.lovecam.uol.com.br $>$.
} 
explicitaram que era proibido, por contrato, passar qualquer contato pessoal via site. 0 objetivo era que as entrevistas fossem realizadas pela internet (via Skype), mas fora dos sites pagos, o que não foi possível. Do mesmo modo, não foi aceito 0 pedido de autorização destinado aos gestores para acessar os sites gratuitamente (ou por um valor reduzido).

Depois desse primeiro obstáculo, encontramos blogs e sites pessoais que anunciavam os serviços de web strippers, espaços estes onde finalmente foi possível, ao mesmo tempo, encontrar mulheres para participar da pesquisa e analisar os próprios sites e blogs, que continham dados muito ricos sobre as strippers e seu trabalho. Mesmo assim, não foi fácil localizar mulheres que se dispusessem a despender seu tempo com a pesquisa, ou encontrar tempo e disponibilidade na apertada agenda de shows para interlocução com aquelas que aceitaram participar, o que demandou muitas horas semanais de conexão à internet por mais de dois anos para a realização da pesquisa de campo.

A pesquisa foi feita com nove mulheres que se dedicavam ao strip-tease on-line comercial, dentre as quais, seis tinham formação superior (ou estavam em curso) nas mais variadas áreas: engenharia, medicina, comunicação social e administração, por exemplo. De vários estados do país, majoritariamente da região Sudeste, três eram casadas, uma divorciada e três namoravam até a finalização da pesquisa. Suas idades variavam entre vinte e um e quarenta e três anos, sendo que seis delas tinham menos de vinte e sete anos à época. Três mulheres se dedicavam a outra ocupação concomitantemente à de web stripper: uma delas era web designer e artista plástica, outra era estagiária em sua área de formação e a terceira era monitora na faculdade em que estudava.

A metodologia adotada foi a etnografia virtual, valendo-se de entrevistas semiestruturadas e conversas informais com as strippers por meio de comunicadores instantâneos. Essa postura interativa e essencialmente dialógica não acompanhou, entretanto, todas as etapas da pesquisa de campo. Nos momentos dos shows coletivos assistidos em diversos sites $^{5}$, a atitude foi sempre a de observador, por considerar que qualquer interferência poderia quebrar sua dinâmica. Pode-se dizer, então, que a observação participante, método fundamental da etnografia, não aconteceu de fato. Mesmo com 0 acompanhamento das atualizações em seus blogs, sites pessoais e nas redes

\footnotetext{
${ }^{5}$ Especialmente no site StripGatas (www.stripgatas.com.br), no qual foram acompanhadas, por três meses, as apresentações de duas strippers envolvidas na pesquisa. Com o slogan "0 primeiro site de strip coletivo do Brasil”, em agosto de 2012 o site encerrou suas atividades para uma reconfiguração de sua dinâmica, não tendo retornado até então.
} 
sociais, a postura do pesquisador no campo pode ser lida como uma observação acompanhante (DÍAZ-BENÍTEZ, 2007), pois não foi deixado neles nenhum depoimento ou qualquer outra marcação pessoal, como também não aconteceu nenhuma interação com as pessoas que buscavam nesses espaços o contato com as strippers.

A proposta deste artigo é, a partir do paradigma da incorporação (CSORDAS, 2008), aliado ao conceito de performance de Butler (2003), pensar como as mulheres pesquisadas ressignificam o corpo, como elas constituem uma outra personagem a partir do seu corpo-mercadoria.

0 comércio de strip-tease on-line envolve técnicas e estratégias das strippers para a construção, representação e exibição do seu corpo. Comumente, essas mulheres percebem seu corpo como uma base material que precisa ser trabalhada, investida por meio de cuidados com a manutenção e/ou aprimoramento da beleza. Além disso, por um processo de pedagogização, elas desenvolvem características e comportamentos a fim de fazerem incidir estereótipos e representações sobre si mesmas dentro do universo erótico. Nesse processo de corporificação (embodiment) (VALE DE ALMEIDA, 1996; JAYME, 2001; BOURDIEU, 2006; CSORDAS, 2008) é possível dizer que elas incorporam outra personagem, com identidade, gênero e nome, com o objetivo de atender aos desejos e expectativas do mercado de web stripper.

Nesse cenário, as strippers se constroem por meio de roupas, gestos e comportamentos, jogos de conquista e linguagem, resultando em imagens comerciáveis de femininos corporificados em acordo com uma estética representada por elas como adequada para a conquista do maior número possível de clientes. Ademais, para que alcancem uma representação estética do sexual vislumbrada como atrativa, e a visibilidade necessária entre a profusão de imagens que compreendem o universo erótico e sexual no ciberespaço, as web strippers empreendem um esforço regular de gestão do corpo, o que implica vários cuidados com a estética. Regidas pela moral da boa forma (GOLDENBERG e RAMOS, 2002), elas, em geral, buscam a adequação do corpo a um padrão estético tido como o de uma "mulher gostosa" por meio de exercícios físicos, de cosméticos, procedimentos estéticos e de uma alimentação balanceada.

Outra condição substancial para que as imagens (fotos, vídeos ou exibições sincrônicas) das web strippers sejam produtos com valor de câmbio no mercado em que se localizam, tem a ver com a capacidade de elas serem, ao mesmo tempo, "uma e várias". A plasticidade é vislumbrada por elas como condição 
essencial para que tenham chances de se destacar nesse cenário e, assim, atingir maiores ganhos:

A gente tem que ser camaleoa, tem que encarnar a virgem, a colegial, a mulher devassa, a funkeira safada etc. de acordo com a fantasia dele [do cliente]. [...] Cada um pede uma coisa diferente e se você não entra na fantasia dele, [ele] procura outra ou não volta mais. Com a quantidade de meninas que estão oferecendo strip então, tem ficado muito concorrido, por isso tem que agradar a clientela para voltar de novo (risos). (Camila) ${ }^{6}$

Esse processo não implica somente na assunção de diferentes personagens ou papéis por parte delas, mas também no constante fluxo e transformação de linguagens audiovisuais e significados que elas materializam a partir do e no corpo. Elas acreditam que devem se colocar como um sujeito moldável, que se destitui provisoriamente de si para que possam incorporar outra personagem que, segundo a demanda, atende aos anseios dos consumidores pela lógica da mercadoria (JAMESON, 2007; APPADURAI, 2008). Essa premissa, no entanto, não é apropriada por elas da noite para o dia, demanda experiência, um "aprender fazendo com o corpo" (VALE DE ALMEIDA, 1996, p. 1), situação em que se capacitam para construir gestos e feições, poses, sonoridades e práticas diversas que compõem a personagem que elas incorporam ante a webcam ou nas fotos e vídeos disponibilizados em seus espaços virtuais ou encomendados e enviados diretamente a seus clientes.

No comércio de strip-tease on-line as mulheres estão constantemente construindo gêneros (BUTLER, 2003, 2005, 2006), seja no momento de seu aprendizado sobre como desenvolver suas performances, isto é, no processo de constituição e incorporação da stripper on-line; seja quando projetam estereótipos de gênero a partir das personagens ou papéis que dramatizam geralmente a partir de uma pauta heteronormativa. É no corpo que esses gêneros são performatizados, pois o gênero tem como base metafórica o corpo e seu modo de expressão. (VALE DE ALMEIDA, 1996).

\footnotetext{
${ }^{6}$ Os nomes usados aqui são os mesmos que elas usam em seus sites e blogs, à exceção de Lara e Camila, que optaram por um pseudônimo, escolhido pelo pesquisador, visto que elas não se prontificaram a defini-lo.
} 


\section{O MERCADO DE STRIP-TEASE ON-LINE: NUDEZ E SEXO NA INTERNET}

Seja por meio de propaganda, agenciamento e negociação de serviços sexuais, seja para o intercâmbio e criação de fantasias e sua realização na própria rede, é fato que internet serve de suporte para a expansão do comércio sexual (PISCITELLI, 2005; CECARELLI, 2008). E a cada época surgem novas variantes, dentre as quais o strip-tease on-line pago é uma modalidade que tem se alargado, segundo o que a etnografia nos apontou.

Nesse mercado, o termo strip-tease não se refere apenas ao desnudar-se. Diferentemente de como um show dessa natureza é muitas vezes representado, em que se evoca um repertório básico de movimentos e gestos corporais sensuais embalados por uma música enquanto o performer tira a roupa, o ponto mais alto das práticas das strippers virtuais, em geral, não está em seu desnudamento e na exibição de seu corpo de maneira mais franca, como geralmente acontece em casas de shows ou boates (ARENT, 2011; NUNES, 2012; VILLAGRÁN, 2012). 0 serviço oferecido pelas strippers via internet, muito em razão da ambiência em que se realiza e por conta das exigências que o mercado coloca no que concerne a seus modos de efetuação, traz consigo novos e distintos repertórios daqueles que se colocam em strip-teases diante de uma plateia física e do imaginário construído sobre essa prática erótica. Entre as realizações mais comuns, elas se masturbam diante da webcam, penetram-se com vibradores, dildos ${ }^{7}$ e outros objetos eróticos, entre tantas outras solicitações dos clientes realizadas na interação. Suas apresentações, então, não se encerram com 0 nu. De modo inverso, é geralmente a partir do despojamento de suas roupas que suas performances ganham maior relevo.

Os pacotes de shows oferecidos pelas strippers em seus blogs e sites pessoais diferem entre eles basicamente em seu conteúdo, duração e preços. A partir da conjugação desses fatores há muitas variações, cujo tratamento foge aos objetivos deste texto. A fim de exemplificar como tendem a acontecer a organização e realização de seus shows, seguem as palavras de Ludmilla:

\footnotetext{
${ }^{7}$ Dildos (consolos) e vibradores são objetos pensados e construídos para a penetração vaginal e anal, sendo que os últimos se diferem dos primeiros em razão de, como o próprio nome indica, vibrarem quando ligados (GREGORI, 2004). No caso das strippers virtuais entrevistadas, é mais comum que usem dildos. Considerando a dificuldade em diferenciá-los a partir de sua visualização e de suas falas, usamos os dois termos aqui indistintamente.
} 
Eu vou fazendo e atendendo aos pedidos, se ele comprou com anal, eu faço [com o uso de vibradores e dildos], se comprou sem não faço, não é bem um roteiro, é como no restaurante, você pede bife com arroz e não adianta reclamar que não veio batata frita, porque você viu previamente que não constava isso no seu prato (pacote) e também não pagou pelas batatas fritas. Não é roteiro não, eu faço o que o show inclui, mas não tem ordem, pois o cara interage e nos shows mais caros ele pode escolher, alguns nem ligam, aí sou eu que escolho.

As performances das strippers ante a webcam, pelo que a investigação indicou, apresentam uma dinâmica que se ancora em duas vertentes: uma homogênea, dado o seu caráter coreográfico e ritualizado, com movimentos, poses, e tempos que tendem, em geral, a se repetir; e outra heterogênea, em que constam as variações de acordo com as convocações dos clientes e as disponibilidades e interditos das strippers, e, evidentemente, os traços pessoais na constituição de suas apresentações. Em comum, nota-se que elas, em suas dramatizações cotidianas, a cada pose, buscam o ângulo que capte todo 0 potencial erótico de cada parte de seu corpo com o objetivo de se materializarem diante dos olhos de seus clientes. Cada fragmento de seus corpos é exibido (inclusive até onde as lentes da câmera alcançam do interior do corpo) para que seja consumido, parte por parte, pelos clientes que buscam a (hiper)visibilidade dos corpos, pois, ao que parece, o prazer está em observar detalhadamente cada fração, cada pormenor. A isso, somam-se gestos, movimentos, poses, sussurros, gemidos e diversas práticas erótico-sexuais que se constituem em mercadorias de caráter espetacular.

Tais representações partem de um ideário coletivo sobre o qual elas se fundamentam para se projetarem como produtos a partir de uma semântica heteronormativa, no sentido de Butler (2003). De acordo com a autora, o gênero é um aprendizado que se dá a partir da repetição reiterada de gestos e signos, como será discutido a seguir. As strippers constituem sua performance nessa iconografia como mulheres hiperfemininas e hiper-sexualizadas, e os textos que comunicam seus serviços em seus blogs e sites pessoais contribuem nesse empreendimento:

Eu realizo as fantasias mais loucas através dos meus shows virtuais eróticos na webcam. Amo conhecer pessoas diferentes e adquirir novas experiências. 0 que me deixa completamente louca e excitada são as conversas quentes e safadas durante os shows eu adoro ver vocês me 
olhando e gozando pra mim. Adoro o sexo virtual, esse desejo oculto de voyeur que todos nós temos (Deusa da Web - retirado de seu blog).

$\mathrm{Na}$ articulação entre o subjetivo e o social, as strippers se constroem performaticamente como imagens meritórias de serem vistas e comercializadas dentro do mercado de strip-tease on-line, num processo que se dá por meio da incorporação de rasgos de certa feminilidade vista como própria para despertar 0 desejo e agradar erótica e sexualmente aqueles que buscam esse tipo de serviço. 0 corpo da web stripper explicita uma experiência feminina fetichizada, de um corpo erotizado e sexualizado.

\section{INCORPORANDO A STRIPPER}

Ante as considerações de que a vida é um decurso corporal, pois, "se o corpo pode simbolizar a existência é porque a realiza e porque é sua atualidade" (MERLEAU-PONTY, 1994, p. 227), já não há mais hesitação nas ciências sociais de que o corpo é um recurso importante para se compreender como se constroem as relações entre as estruturas sociais e simbólicas e a ação individual. Tal recurso possibilita entender a complexidade da experiência humana, a organização social e como são produzidos seus sentidos.

0 corpo é base da subjetividade humana e da vida, portanto, uma experiência incorporada que se realiza pelo reconhecimento de si mesmo e do mundo pelos sentidos (MERLEAU-PONTY, 1994). o corpo subjetivo é uma estrutura dinâmica que se modifica e se transforma a todo instante em contato com o meio e com os outros, o que faz da existência corporal uma coexistência com 0 mundo. Por ser construído nas experiências humanas, ele nunca está pronto, pois em toda a sua existência é perpassado pela história, por discursos sociais, religiosos, estéticos, culturais, políticos e econômicos. Como assevera Vale de Almeida (1996, p. 14), o corpo representa "processos de atividade auto produtiva, ao mesmo tempo subjetiva e objetiva, significativa e material, pessoal e social, um agente que produz discursos como também o recebe".

Com as novas tecnologias de informação e comunicação, a experiência corporal têm ganhado novos sentidos, pois as ideias de presença e ausência, de proximidade e distância, seja espacial, seja temporal têm se modificado de forma substantiva. Virtualmente, o corpo transpõe barreiras geográficas, possibilitando novas experiências, indicando que os modelos de subjetividade praticados no ciberespaço manifestam os modos particulares de agência de cada sujeito no mundo virtual de acordo com o contexto, com os objetivos e com as interações 
levadas a cabo (LEWGOY, 2009). Tais experimentações não indicam a desmaterialização do corpo em suas vivências no ciberespaço, mas seu redimensionamento que amplifica as possibilidades de sua (des)construção e vivência.

Em acordo com os desejos, as expectativas e a inventividade daqueles que, por exemplo, buscam interações de caráter sexual na internet, são evocadas outras formas de interação, de toque e de sensibilidade. Reinventam-se o corpo e as relações sexuais (SILVA \& SEBASTIĨ̃), 2002; SALDARRIAGA \& BARRERA, 2008; SILVA, 2008). A ideia do ciborgue, discutida por Donna Haraway (2000), vai ao encontro do que está sendo colocado aqui. Ao venderem o serviço de strip-tease pela internet, as mulheres ressignificam não apenas o strip-tease, mas o próprio encontro sexual, que, realizado pelas ondas da rede de computadores, explicitamente, revela seu vínculo com a tecnologia. 0 que se vê do outro lado do computador? Uma imagem ou uma mulher? Mas não é só isso. Como se verá, ao construírem o seu corpo para vender esse tipo de serviço, as web strippers usam de tecnologias disponíveis nas máquinas das academias de ginástica, por exemplo. Como afirma Kunzru sobre o fato de Donna Haraway se auto-denominar como um ciborgue e como dizem as web strippers sobre a preparação do seu corpo para o trabalho:

Ser um ciborgue não tem a ver com quantos bits de silício temos sob nossa pele ou com quantas próteses nosso corpo contém. Tem a ver com o fato de Donna Haraway ir à academia de ginástica, observar uma prateleira de alimentos energéticos para bodybuilding, olhar as máquinas para malhação e se dar conta de que ela está em um lugar que não existiria sem a ideia do corpo como uma máquina de alta performance. (KUNZRU, 2000, p. 25-26).

Eu voltei para a academia, porque é muito importante para o corpo, né? (Suzi)

Eu malho de manhã e estudo à noite. A principal coisa que faço [referente aos cuidados com o corpo] é malhar (Jujuba)

Não dá para malhar todo dia, mas vou sempre que posso porque é essencial para ter um corpo bonito. Ainda mais nesse tipo de trabalho. (Lara) 
A partir do conceito de incorporação (embodiment), Csordas (2008) propõe a elaboração de um paradigma antropológico que busca o rompimento definitivo com aspectos dualistas no estudo do corpo. Propõe que o corpo pode ser construído ao mesmo tempo como fonte de representações e como fundamento do ser/estar-no-mundo, isto é, deve-se considerar a possibilidade de que a representação pode ser compreendida como constitutiva da experiência e da realidade enquanto textos. Assim, o corpo além de poder ser reconhecido como um objeto sobre o qual a cultura opera, deve ser vislumbrado como o local das percepções, a partir das quais a cultura "vem a ser". Importa significativamente a experiência vivida dos sujeitos, considerando-a como processo temporal e historicamente determinado, o que implica dizer que o corpo está imerso em um campo político e, em razão disso, é motivo de interpelação normativa.

Em perspectiva diferente, mas que coincide em alguns pontos com a teoria desse autor, Butler (2003), manifesta que, em sua materialização em qualquer cultura, os corpos, para serem inteligíveis, precisam fazer sentido dentro de determinada sociedade, ou seja, precisam ser reconhecidos. A primeira e principal marca, segundo a autora, está na inscrição semântica de gênero, que antepõe masculino e feminino. E, como já dito, esta marca é impressa antes mesmo do nascimento da criança, na sala de ultrassonografia, quando a/o médica/o diz: é um menino ou é uma menina. A partir dessa impressão, aprende-se reiteradamente (repetindo ritualisticamente as normas) o que é (pode ser) ser/se portar como uma menina e/ou um menino. 0 que está fora dessa norma não é visto como sujeito, já que não é inteligível, seria o abjeto (BUTLER, 2005, 2006).

Atravessados por diversas tecnologias, discursos institucionalizados e práticas cotidianas, os sujeitos se constroem enquanto corpos masculinos e femininos na expectativa de manter 0 gênero em sua estrutura binária que têm sua base assentada na ideologia da heterossexualidade (DE LAURETIS, 1994; BUTLER, 2003, 2005, 2006). Vão sendo demarcadas características corporais a partir do gênero dos sujeitos, outorgando direcionamento nas percepções, ações e usos do corpo em várias perspectivas. Assim, em um processo sócio-histórico, os corpos vão assumindo características que as sociedades lhe consagraram ao longo do tempo, organizando o mundo de forma dual, dividindo-o em masculino e feminino, de maneira hierarquizada, inclusive dentro das mesmas categorias (VALE DE ALMEIDA, 1996).

0 gênero, então, faz parte do mapa cognitivo com que os sujeitos operam, não sendo, entretanto, uma estrutura sólida, duradoura, intrínseca ao indivíduo; é construído socialmente ao longo do tempo por meio da incorporação de gestos, 
movimentos, práticas, disposições corporais masculinas e femininas, regras e estilos pelos sujeitos, perpassado e influenciado consecutivamente pelas expectativas sociais de cada contexto histórico e social. As feminilidades e as masculinidades são fluidas e relacionais, às quais importam a raça, a classe e a orientação sexual, dentre outras instâncias; estão num campo constantemente em disputa e transformação, que se situa no interior de relações de poder.

Esse complexo semântico convertido em prática social é para Butler (2003, 2005, 2006) uma questão de performatividade. Para a autora, o gênero é performativo justamente por se tratar do aprendizado de normas de atitude, comportamento, gestos etc., cuja repetição ritualística reforça seu efeito naturalizante. Ao fim e ao cabo, para Butler o gênero pode ser entendido ele próprio como norma, ainda que esta norma não seja nunca totalmente incorporada. Subordinados a essa estrutura de poder, a atuação do sujeito de acordo com o lugar que lhe foi destinado e cujas prescrições ligadas a ele devem ser seguidas, está sempre condicionada a recompensas e castigos. Mas, a autora deixa claro que desenvolver uma performance de gênero não significa dizer que 0 gênero seja uma escolha pessoal, voluntarista, realizado a partir das preferências e experiências individuais. Há, antes, uma tensão, dado que dita performance é um fenômeno que parte da dialética entre os sujeitos e a sociedade, sendo constituída/aprendida nos processos sociais. Ou seja, esses processos que se relacionam na constituição e manutenção da performance são determinados pela estrutura social, o que nos remonta à ideia de que o gênero tem forte vínculo com a atribuição social.

(...) a matriz das relações de gênero é anterior à aparição do "humano". Consideremos o caso da interpelação médica [...] que passa transforma "o bebê" em "o menino" ou "a menina" e a menina se feminiliza mediante essa denominação que a introduz ao terreno da linguagem e ao parentesco através da interpelação de gênero. Mas essa feminilização da menina não termina aí, pelo contrário, as diversas autoridades reiteram-na ao longo do tempo [...]. A denominação é um modo de fixar uma fronteira e também inculcar repetidamente uma norma (BUTLER, 2005, p. 25-26).

É justamente a repetição que resulta na eficiência dos atos performativos e que propicia a base para a constituição das identidades de gênero pautadas na estrutura binária. Para a autora, o gênero está diretamente ligado ao corpo, o que significa dizer que a performance de gênero está relacionada a estilos corporais, 
estando esses submetidos a um sistema de dominação patriarcal. 0 corpo, pois, é pensado como uma "superfície politicamente regulada", constituída histórica e socialmente.

Diante disso, ao se tratar da relação entre o corpo, o mundo, o social e 0 cultural favorecida pelo paradigma da incorporação e sua relação com a performance de gênero, podemos refletir sobre como as strippers têm o corpo convertido em espaço sobre o qual se inscrevem significados sociais e culturais que aludem à associação na categoria de profissional do comércio sexual, em acordo com os ambientes de socialização com seus pares e prática profissional dentro de uma estrutura social mais ampla. Considerando que é no corpo que se realiza sua performance, reconhece-se que essas mulheres são uma construção sócio-histórico-cultural, que tem como constituinte primário e essencial o corpo, espaço-tempo em que estão inscritos posturas, gestos, atitudes, posicionamentos e comportamentos. Sua ocupação demanda técnicas específicas (e recursos tecnológicos), cujo aprendizado é construído pela strippers na socialização com seus pares e no transcorrer de sua experiência com os clientes.

Lara, por exemplo, sem nunca ter se exibido antes na webcam, afirmou que quando viu chances de ganhar dinheiro com strip-tease na internet, buscou vídeos desse gênero no Youtube para aprender alguns movimentos básicos, a fim de conseguir construir uma performance elementar que, com o tempo, foi ganhando novos gestos e fluxos a partir de sua experiência. Contou, inclusive, que o espelho foi um recurso importante no princípio, pois a partir do reflexo de sua imagem foi aprendendo como se posicionar diante da webcam, quais movimentos deveriam ser mais pausados, em detrimento de outros mais dinâmicos, e como dar maior sentido erótico à dança usando expressões faciais e as mãos. 0 segmento do show que ela considerou mais complicado nesse processo de incorporação foi 0 que costuma vir pós-desnudamento: masturbação e cenas de sexo com penetração.

É completamente diferente você [se] masturbar sozinha e para alguém que te paga. No começo eu ficava travada, nem conseguia relaxar, ficava com vergonha, medo de tá muito feio para quem via. Eu acho até que era bem artificial. Eu não conseguia fazer direito. Depois de alguns shows fui aprendendo como é, como parecer que eu estou curtindo [...] Às vezes eu curto sim, mas não é sempre.

Ludmilla também nunca havia se exibido antes na internet. Assim que vislumbrou a chance de ganhar dinheiro com shows on-line, disse que comprou 
uma webcam com esse propósito e que aprendeu como se apresentar com a prática.

Acho que hoje eu domino melhor a cam e as posições, fiquei mais familiarizada com a coisa, antes eu só conseguia mostrar enfiando o brinquedo em pé, porque a cama ficava longe e o fio da cam era curto. Hoje eu tenho notebook, cam com fio longo e $H D$, tudo ficou mais profissional, a internet mais rápida, iluminação e cor de parede tudo de caso pensado (risos).

Camila e Luana, por exemplo, já haviam se exibido na internet gratuitamente antes de vislumbrarem o strip-tease como oportunidade financeira. Tais mostras tinham caráter amador, não eram apresentações previamente pensadas, com rigor ou qualquer roteiro, "porque fazia por diversão, gosto de me exibir e interagir com as pessoas na cam", conforme Camila faz questão de destacar. Ao entrarem no mercado do sexo, para que suas apresentações ganhassem características que reportassem à expertise e à profissionalização, elas empreenderam recursos e ardis. Seus comentários a esse respeito nos ajudam a entender melhor essa transposição:

Quando resolvi entrar para valer nessa, eu vi que tinha que melhorar muita coisa. É outro nível, né? [...] Para ganhar dinheiro, conseguir clientes, tive que fazer muita coisa. Arrumar roupas, principalmente lingeries mais bonitas, comprar uma webcam melhor, aumentar minha internet [referindo-se à velocidade], a luz do quarto, comprar vibrador que eu não tinha, essas coisas que a gente costuma usar [...] 0 principal e que demorou mais foi saber fazer um strip bem feito, de um jeito bem sensual, tirando a roupa de jeito certo, de jeito bem feminino, como naqueles [strip-teases] que a gente vê em filme. $\mathrm{E}$ também usar de jeito bacana o vibrador. Não é só colocar não, tem que ver o ângulo da cam, com o corpo na posição pro cara ver direito. Dá trabalho. E o povo acha que a gente está só se divertindo aqui (Camila).

Fui aprendendo sozinha, aliás, ia sempre perguntando sempre para 0 cliente, sobre o que queria, se estava certo, em que deveria melhorar. 0 que ajudou é que me identifiquei com a webcam e ia tentando melhorar mais a cada dia (Luana). 
Como se nota, elas ressignificam o corpo a partir de um complexo de critérios e esquemas constituídos culturalmente no comércio sexual, a fim de agradar seus clientes e possibilitar a conquista de novos shows a ser realizados. Mais uma vez, aqui se explicita um mundo próximo àquele a que Donna Haraway (2000) se refere no seu Manifesto, ou seja, um mundo em que o humano e a máquina estão misturados. "O ciborgue é uma matéria de ficção e também de experiência vivida..." (HARAWAY, 2000, p. 40), um mundo em que dualismos como mente-corpo, organismo-máquina, natureza-cultura, entre outros, não estão claros.

\section{CORPOS ERÓTICOS EM CENA}

Ao incorporarem a stripper, as mulheres com quem conversamos desempenham, por sua vez, diferentes papéis (ou fantasias) de acordo com as demandas dos clientes. Nesse rol, os perfis assumidos acionam, muitas vezes, estereótipos representados como próprios do imaginário erótico-sexual contemporâneo, o que se pode observar em imagens midiáticas comumente divulgadas em instâncias diversas. Em uma composição hiperbólica, marcada pelos efeitos de gênero, estão presentes as figuras da Lolita, da mulher devassa, da estudante sexy, da enfermeira, da empregada doméstica, da dançarina de funk, dentre outras. Para tanto, essas mulheres reconfiguram símbolos visuais e discursivos a fim de expressarem, no momento da encenação, o real efeito e presença desse $e u$ incorporado do papel assumido a partir do uso criativo e tecnológico do corpo. Isto é, na performatização ante a câmera, elas buscam a cada dia, em uma cinesiologia particular, o aperfeiçoamento dos movimentos, das poses, ângulos, feições e onomatopeias que visam tornar o espetáculo prazeroso de ser visto e revisto pela audiência, conforme percebido nos excertos acima.

Dessa forma, elas projetam para os clientes a imagem de um outro eu que, a seu turno, provavelmente também estão envolvidos nesse processo de autoinvenção, visto que eles também não se desfazem de suas máscaras, estão atuando o tempo todo, porque, quando da interação com as strippers, assumem um papel destacado no jogo, também por se sentirem mais seguros com garantia de anonimato e "impossibilidade" de serem descobertos.

Luana é uma personagem, ou melhor, várias. Cada cliente tem de mim aquilo que quer. [...] Na hora do show é como se não fosse eu (risos), descubro a Luana. [Primeira fase de entrevistas]

[...] 
Tudo mudou ${ }^{8}$ [desde setembro de 2011], meu nome, meu jeito de atender, meu perfil, meus lucros, tudo.

Entrevistador: Mas e a Luana, não existe mais?

Luana: Não, morreu (risos). Me apelidaram de Peludinha e aos poucos fui me esquecendo disso e me acostumei com o novo nome. Sou outra agora [Quando o contato foi retomado].

Entrevistador: Você tem quantos anos?

Suzi: Suzi tem 31, eu tenho 35.

Entrevistador: Pensemos que você se chama Ana. 0 que a Ludmilla tem da Ana?

Ludmilla: Ana não (rsrsrs) Maria. (kkkk)... Tem pouca coisa. A Maria é mais reservada, usa roupas mais discretas... 0s clientes acham que sou uma baladeira, que saio de vestidinho estilo piriguete. [...] Volta e meia falam, pedem vestidinhos de piriguete e dizem "daqueles que você usa pra sair".

Entrevistador: E o que você responde?

Ludmilla: Finjo que sim, tenho os vestidos, mas só pra webcam mesmo. Entro na fantasia dele...

Entrevistador: Mas como a Maria se transforma em Ludmilla? Não me refiro só a roupas...

Ludmilla: Quando eu ligo a webcam eu encarno um personagem que é uma mulher cheia de fogo e com tesão 24 horas por dia, disposta a agradar, sempre alegre, sorridente.

Você está querendo dizer como eu me transformo em Camila? Eu não sou tímida, o que ajuda (risos). [...] Gosto de me exibir na net, mas no dia a dia não costumo usar essas roupas não. Algumas roupas até são as mesmas, mas eu uso de um jeito diferente sabe [...] encurto a saia, uso uma camiseta transparente sem sutiã e assim vai [...] Outras não uso na rua de jeito nenhum, só para show mesmo. Não sou vulgar, a Camila é (Camila).

\footnotetext{
${ }^{8}$ No transcorrer da etnografia, perdemos o contato com Luana por mais de um ano. Passado esse período, descobrimos que estava trabalhando somente em um site (http://www.camerahot.com/profile/Peludinha) e que muita coisa havia mudado, a começar pelo seu nome. Diante disso, ela propõe: "Olha, se puder, podemos começar do zero, tudo de novo, [pois] tudo mudou aqui (risos)".
} 
Como podemos notar em suas falas, elas movem destacado esforço no sentido de construir uma personificação que se converta em objeto de desejo nos vários processos de interação que os clientes mantêm com elas, desde os primeiros contatos que eles têm com sua imagem a partir de suas fotos, vídeos e textos em seus blogs e sites pessoais. Há, pois, um investimento - no sentido de incorporação (CSORDAS, 2008) - em que buscam acumular capital simbólico em uma construção corporal que remeta à sensualidade, ao erotismo e à sua constante disposição para as interações dessa natureza. Esse processo, no entanto, não acontece da noite para o dia. Demanda tempo, uma aprendizagem que acontece na prática, principalmente porque há, em geral, a preocupação por parte delas em agregar novos contornos a seus shows e com o aprimoramento de suas performances para que os clientes encontrem motivos para contratá-las novamente.

Desse modo, nas encenações erótico-sexuais levadas a cabo, elas colocam em prática variadas estratégias e técnicas de sedução aprendidas por meio do processo de experimentação e socialização em várias instâncias. Sua maneira de olhar, de mover o corpo, de se vestir, do que e de como exibir, os detalhes mostrados dos seios, língua, boca, glúteos e genitais, desvelando os traços de desejo e de sexualidade são disposições corporais que condizem com sua função e com o lugar que ocupam.

A conversão dos sujeitos da pesquisa em web strippers, isto é, em mulheres com as características representadas por elas como essenciais para prestar esse serviço, muitas delas notadamente expressas nos excertos de suas falas apresentados, depõe em favor da ideia de que o corpo não é um fato isolado de seu contexto, um destino inescapável, mas justamente o contrário; é um processo nunca terminado, com muitas possibilidades em seu desenvolvimento, no qual femininos (e masculinos) são identidades incorporadas, sendo que a noção de identidade prévia de gênero não passa de uma ilusão (BUTLER, 2003). Ao construírem o corpo por meio do rosto maquiado em excesso, de roupas sensuais (e da utilização diferenciada do vestiário comum, usada fora do trabalho, como anuncia Camila), acompanhadas de sapatos altos e chamativos, de gestos, olhares e outras disposições corporais representados como provocantes e sedutores, fica evidente que elas incorporam um (ou muitos) novo eu que tem inclusive outro nome para momentos muito específicos - fotos e vídeos de divulgação ou encomenda de algum cliente e para as encenações diante da webcam, nos quais opõem a vida de stripper, de sua vida "fora do mercado de trabalho", isto é, de sua vida privada. 
Assumir a stripper virtual exige que essas mulheres se destituam momentaneamente de si mesmas e assumam uma personagem que possui características estéticas e comportamentais que se diferem, muitas vezes, desse eu que foi "esvaziado" naquele momento. Tal situação implica para algumas delas ultrapassar barreiras individuais, visto que essa transposição exige que assumam posturas e comportamentos que não condizem com seu modo de vida e gostos pessoais.

Entrevistador: 0 que a Lara tem da Márcia ${ }^{9}$ ?

Lara: Quase nada, eu acho. Eu sou assim, tímida, mais tranquila, gosto muito de ficar em casa, ler, ver filmes e a Lara parece não gostar disso não (risos). Ela é assim, como vou dizer, mais sapeca (risos). Ela usa roupas e tem comportamentos diferentes de mim [...] Já a Lara não tem vergonha não, ela é mais liberal, atrevida. Claro que não foi fácil no início porque eu tive que trabalhar isso comigo. Eu não consigo ser assim, não me sinto tão à vontade. Acho que deve ser por causa da minha criação, sei lá (Lara).

Da minha personalidade, sou uma pessoa tranquila, quieta, tímida, mas meus clientes me veem de maneira oposta, afinal, é tudo o que deixo perceberem de mim (Jujuba).

A transitoriedade entre esses dois mundos e, especialmente 0 ato de (re)construir cotidiana e ritualmente o próprio corpo, diz respeito à expressão e comunicação de uma multiplicidade de personagens, situação que não é experimentada e vivida por alguns dos sujeitos de pesquisa como isenta de tensão e muito cuidado. Para aquelas que escondem da família e de outras pessoas próximas a forma como ganham dinheiro, principalmente as que moram com os pais, esse jogo é perpassado constantemente pelo suspense e medo de serem descobertas, o que faz com que o processo cotidiano de assunção da stripper seja ainda mais complexo.

Tais colocações nos levam a discernir que as mulheres postas em cena na webcam, enquanto realizam seu trabalho, não existem antes das encenações, mas que se constituem nos momentos que antecedem os shows e ao desenvolverem e levarem a cabo as práticas que compõem suas performances.

\footnotetext{
${ }^{9}$ Lara é o pseudônimo utilizado na etnografia. Márcia foi usado para diferenciar a stripper da identidade pessoal (fora do trabalho).
} 
Outro fator importante na constituição da web stripper é seu nome. Geralmente é a partir dele que os clientes têm o primeiro contato com elas, seja por meio da indicação de alguém ou da propaganda em algum site, ou mesmo ao procurar o serviço de strip-tease on-line em alguma plataforma de busca. Esse nome, portanto, não é neutro, ao contrário, é escolhido a partir de um arcabouço que concentra seu gosto pessoal e, particularmente, que esteja ligado à imagem que almejam projetar nesse mercado. 0 novo nome diz respeito a outra mulher, com corpo, subjetividade e características próprias, às vezes, muito destoantes de seu outro eu. O nome está atrelado à identidade e, como esta, não é necessariamente fixo ou mesmo rígido. Elas buscam, pois, associar seu nome às imagens que farão com que sejam lembradas e reconhecidas nesse mercado, 0 que lhes imputa a gerência contínua de fotografias, vídeos, textos e também depoimentos dos clientes no intuito de que seu nome esteja sempre vinculado ao erotismo e ao prazer sexual.

Os nomes adotados por elas quase sempre partem de uma simbologia de conotação erótica, sendo alguns exemplos Deusa da Web, Peludinha, Bruna Sweet, Jujuba $^{10}$. Assim, o nome representa para elas um recurso essencial para que sejam lembradas e desejadas, uma primeira impressão, uma espécie de corpo que anuncia o que estão dispostas a oferecer, o que faz com que a designação do nome lhes exija, de maneira geral, agudas ponderações a esse respeito. Como sou uma Deusa, eles [os clientes] são meus súditos. Tem muito cliente que me trata assim mesmo, o nome pegou e ajuda na fantasia dos clientes. (Deusa da Web).

Os nomes, pois, são escolhidos por elas com o objetivo de expressar o que as pessoas podem esperar delas, a forma como elas querem ser percebidas e também em conciliação com o que consideram como o enunciado semântico que poderá despertar o maior interesse para um grande número de clientes. É por meio do nome e do corpo que a pessoa se expressa socialmente e se mostra, em uma experiência corporizada e localizada que, em um processo sempre inacabado, compõe gêneros e subjetividades. Ao buscarem atender aos desejos e expectativas dos clientes em seus shows a fim de produzirem mais dinheiro, as strippers assumem comportamentos diferentes que demandam a evocação de corpos também distintos, de acordo com a performance empreendida. Significa dizer que os corpos são múltiplos, pois são (re)construídos segundo a intenção do sujeito, o contexto no qual se inserem e também de acordo com a forma com que

\footnotetext{
${ }^{10}$ Camila e Lara também têm nomes com demarcada conotação erótica, mas como preferiram que não fossem divulgados, optamos por dar-lhes um nome comum, já que nenhuma delas se prontificou a escolher um pseudônimo.
} 
são interpelados. É possível considerar, pois, na perspectiva de Rago (2000) ao tratar da prostituição feminina, que no comércio do sexo há também por parte das strippers um nomadismo sexual dos corpos, relacionado não tão-somente pelo número de clientes atendidos a cada dia, mas também pelos usos sexuais do corpo. Algumas expressões são bastante elucidativas sobre as dinâmicas de seu trabalho:

Você comanda seu show! (anúncio comum à maioria delas)

Falo o que você quer ouvir [e] faço gozar muito gostoso! (Deusa da Web)

Posso ser quem você quiser! (Lara)

Se você é escravo e curte uma dominação virtual veio ao lugar certo! (Ludmilla)

Você pede, eu faço! (Jujuba)

A assunção de diversos papéis, portanto, bem como das modalidades de shows oferecidos, é uma estratégia evocada constantemente pelas strippers que geralmente se baseia nas escolhas, desejos e expectativas de cada cliente. Às vezes, de um show a outro, cujo intervalo pode ser mínimo, é necessário que elas incorporem um tipo completamente diferente do anterior. E conforme Lara afirmou em certo trecho de seus depoimentos sobre os papéis que tem que interpretar, não é tão fácil não, não é só trocar de roupa, tem a ver com um envolvimento também. Ou seja, tem que ver com uma construção corporal, que reclama a admissão de vários papéis diferentes em seu cotidiano de trabalho.

\section{CONSIDERAÇÕES FINAIS}

Com corpos produzidos para o gozo e para o prazer visual, as strippers virtuais investigadas têm como foco as representações dos desejos dos sujeitos com efeitos consumistas, desejos esses que não estão atrelados apenas às marcas subjetivas, mas também às imagens construídas social e culturalmente com base na matriz heterossexual. Para tanto, tais mulheres são levadas a desenvolver várias representações que simbolizam "a mulher" por meio de distintos estereótipos, dentre os quais os de mulher fatal, virgem, estudante etc.; que funcionam por meio de roupas, histórias, gestos e disposições corporais que simulam situações potencialmente reais e, justamente por conta dessa condição, incitam o desejo e prometem o gozo aos clientes que anseiam por um espetáculo de strip-tease e/ou sexo on-line. 
Os modos como aprenderam a se apresentar performaticamente e a interagir com os clientes, destacadamente no que se refere a cibersexo se deu, em geral, na realização do ato em si, em um aprender imitando com o corpo (VALE DE ALMEIDA, 1996), na própria realização do corpo, em que se buscava a cada dia, em uma cinesiologia particular, o aperfeiçoamento dos movimentos, das poses, ângulos, feições e onomatopéias que tornassem o espetáculo prazeroso de ser visto e revisto pela audiência.

Julgamos relevante enfatizar que 0 corpo, fundamento onde 0 percurso social da stripper se constrói, não é único, tampouco unificado e coerente, está em constante mutação, principalmente se não perdemos de vista que 0 ser humano "não vive num ambiente meramente físico, mas num universo de sentido (LE BRETON, 2009, p. 75). Assim, a transformação contínua do corpo das strippers acontece principalmente no empreendimento de estar sempre apropriado à "situação de mercadoria" (APPADURAI, 2008), seja por meio da demanda de atendimento aos apelos dos padrões estéticos considerados como adequados à função, como também na implementação de novidades para 0 mercado de strip-tease, que se constituem principalmente na assunção de novas disposições corporais, práticas diferentes e encenação de novas personagens. Neste ponto, a competência da stripper consiste em projetar estereótipos e representações sobre 0 feminino, nos quais 0 gênero é constantemente reinventado no aprimoramento de si enquanto mercadoria ou no investimento das personagens que traz em seu cotidiano. Entre ser uma e ser várias, a estética corporal e as experiências dessas mulheres enquanto strippers têm relação com os desafios de romper com barreiras individuais e também com as marcas do social. Tais rupturas, não obstante, não são jamais completas, mas fissuras estabelecidas que possibilitam que elas promovam outras experiências que aquelas concebidas e preconizadas pela heteronormatividade.

\section{REFERÊNCIAS}

APPADURAI, Arjun. Introdução: mercadorias e políticas de valor. In: APPADURAI, Arjun. A vida social das coisas. As mercadorias sob uma perspectiva cultural. Niterói: EdUFF, 2008.

ARENT, Marion. Gênero, Desejo e Erotismo: Um Caso de Comparação entre "Clubes de Mulheres" em Buenos Aires e no Rio de Janeiro. Cuadernos de Antropología Social No 34, Buenos Aires, 2011. p. 69-92. 
BOURDIEU, Pierre. 0 camponês e seu corpo. Revista de Sociologia e Política, no. 26. Curitiba, jun/ 2006 p. 83-92.

BUTLER, Judith. Problemas de gênero: feminismo e subversão da identidade. RJ: Ed. Civilização Brasileira, 2003.

BUTLER, Judith. Cuerpos que importan: sobre los límites materiales y discursivos del "sexo". Buenos Aires: Paidós 2005.

BUTLER, Judith. Deshacer el gênero. Buenos Aires: Paidós, 2006.

CECCARELLI, Paulo Roberto. Prostituição - corpo como mercadoria. Mente \& Cérebro - Sexo, v. 4 (edição especial), dez. 2008.

CSORDAS, Thomas. A corporeidade como um Paradigma para a Antropologia. In: CSORDAS, Thomas. Corpo/significado/cura. Porto Alegre: Editora UFRGS, 2008.

DE LAURETIS, Teresa. A tecnologia de gênero. In: HOLANDA, Heloisa Buarque de (Org.). Tendências e impasses: o feminismo como crítica cultural. Rio de Janeiro, Rocco, 1994.

DÍAZ-BENÍTEZ, Maria Elvira. Dark Room aqui: um ritual de escuridão e silêncio. Cadernos de Campo. São Paulo, n. 16, 2007.

GOLDENBERG, Mirian e RAMOS, Marcelo. A civilização das formas: o corpo como valor. In: GOLDENBERG, Mirian. $N u$ \& Vestido: dez antropólogos revelam a cultura do corpo carioca. RJ: Record: 2002.

GREGORI, Maria Filomena. Prazer e perigo: notas sobre feminismo, sex-shops e S/M. In: PICITELLI, Adriana, GREGORI, Maria Filomena e CARRARA, Sérgio.

Sexualidades e saberes: convenções e fronteiras. Rio de Janeiro: Garamond, 2004.

HARAWAY, Donna. Manifesto ciborgue: ciência, tecnologia e feminismo-socialista no final do século XX. In: SILVA, Tomás Tadeu da. Antropologia do Ciborgue: as vertigens do pós-humano. Belo Horizonte: Autêntica, 2000.

JAMESON, Fredric. Pós-modernismo: a lógica cultural do capitalismo tardio. São Paulo: Ática, 2007.

JAYME, Juliana Gonzaga. Travestis, Transformistas, drag-queens, transexuais: personagens e máscaras no cotidiano de Belo Horizonte e Lisboa. Tese de doutorado, Ciências Sociais, Universidade de Campinas, 2001. 
KUNZRU, Hari. "Você é um ciborgue": um encontro com Donna Haraway. In: SILVA, Tomás Tadeu da. Antropologia do Ciborgue: as vertigens do pós-humano. Belo Horizonte: Autêntica, 2000.

LE BRETON, David. As Paixões Ordinárias: Antropologia das Emoções. Petrópolis, Vozes, 2009.

LEWGOY, Bernardo. A invenção da (ciber)cultura: virtualização, aura e práticas etnográficas pós-tradicionais no ciberespaço. Civitas, v. 9, n. 2, mai-ago, 2009, p. 185-196.

MERLEAU-PONTY, Maurice. Fenomenologia da Percepção. São Paulo: Martins Fontes, 1994.

NUNES, Claudio Ricardo Freitas. Trazendo a noite para o dia: apontamentos sobre erotismo, striptease masculino, pedagogias de gênero e sexualidade. Tese apresentada ao Programa de Pós-Graduação em Educação da UFGRS, 2012.

PISCITELLI, Adriana. Viagens e sexo on-line: a Internet na geografia do turismo sexual. In: Cadernos Pagu (25), julho-dezembro de 2005. Disponível em: < http://www.scielo.br/pdf/cpa/n25/26530.pdf> Acesso em: 18.12.2010.

RAG0, Margareth. Os prazeres da noite: prostituição e códigos da sexualidade feminina em São Paulo, 1890-1930. São Paulo: Paz e Terra: 2008.

SALDARRIAGA, Diana Ujueta \& BARRERA, Martín Emilio Gáfaro. Amor a primer "clic". El ciberespacio: un lugar donde todo se vuelve líquido. Informes Psicológicos, Vol. 10, No. 11 p. 121 - 141, Medellín - Colombia. Jul-Dic de 2008. SILVA, Carlos Alberto da \& SEBASTIÃO, Pedro Miguel. Interacção \& Cibersexo no IRC. In: SILVA, Carlos; SEBASTIÃO, Pedro. Sociologia em Diálogo. Évora: Universidade de Évora, 2002. Disponível em: < http://www.bocc.uff.br/pag/silvacarlos-sebastiao-pedro-interaccao-cibersexo.pdf> Acesso em $27 \mathrm{dez} .2010$ SILVA, Carolina Parreiras. Sexualidades no ponto.com: espaços e homossexualidades a partir de uma comunidade on-line. Dissertação de Mestrado, Antropologia Social, Universidade Estadual de Campinas, 2008.

SILVA, Weslei Lopes. O sexo incorporado na web: cenas e práticas de mulheres strippers. Tese de Doutorado, Ciências Sociais, Pontifícia Universidade Católica de Minas Gerais, 2014.

VALE DE ALMEIDA, Miguel. Corpo presente: antropologia do corpo e da incorporação. VALE DE ALMEIDA, Miguel. Corpo presente: treze reflexões antropológicas sobre o corpo. Portugal: Celta, 1996. 
VILLAGRÁN, Gilberto López. La emergencia del table dance en el contexto del Tratado de Libre Comercio en México - Impacto simbólico y descomposición de su oferta erótica. CS No. 10, 131-166, jul.-dic. 2012. Disponível em: <file://C:/Users/Usuario/Downloads/1357-4327-1-PB.pdf> Acesso em: 11. 03.2013 .

VIRILIO, Paul. El Cibermundo, la política de lo peor: Entrevista con Philippe Petit. Madri: Ediciones Cátedra, 1997. 